\title{
Awareness and attitudes towards demand response programs - a pilot study
}

\author{
Paula Ferreira \\ ALGORITMI Research Centre \\ University of Minho \\ Guimarães, Portugal \\ paulaf@dps.uminho.pt
}

\author{
Ana Rocha \\ ALGORITMI Research Centre \\ University of Minho \\ Guimarães, Portugal \\ anarocha8420-440@hotmail.com
}

\author{
Madalena Araújo \\ ALGORITMI Research Centre \\ University of Minho \\ Guimarães, Portugal \\ mmaraujo@dps.uminho.pt
}

\begin{abstract}
Electricity planning tends to focus on the generation options mix and largely relies on pre-defined assumption on the demand growth. However, energy end-use has a large potential for improvement and adaptation to the new challenges of the electricity system. The demand response (DR) strategies must then be properly considered in electricity decision making, as relevant options to deal with the variability of the system and ensure in balance at an affordable cost. Although this is not a new concept, the popularity of these DR programs is growing, driven by the increasing opportunities that emerged with smart grid appliances and also by their potential to support the integration of variable renewables generation. The consumer has then a key role on the effective implementation of these DR programs. However, the complexity of the DR topic can create barriers to the communication to public in general and consequently can limit the consumers understanding of the overall concepts and related technologies. This work aims to address this gap and presents the results of an exploratory study supported on a questionnaire directed towards an academic sample of students from one university in Portugal. The results demonstrate that DR solutions are well accepted and could be implemented at large scale, although with limited flexibility. Aspects related to cost savings, contribution to environmental protection and reduction of importations at the national level are found to be important motivating factors, to be explored in future communication actions. However, it should be highlighted that these results cannot be dissociated from the population of the study, which target mainly well informed, young people with a high appeal for new technologies.
\end{abstract}

Keywords- demand response; consumer awareness; acceptance

\section{INTRODUCTION}

The residential energy use represents a significant share of the total electricity consumption which reached more than $26 \%$ in 2015 in EU-28 (own calculation from EUROSTAT data) and almost 28\% for Portugal in 2016 (own calculation from DGEG- Direção Geral de Energia e Geologia website consulted on May 2018). It is then increasingly evident that the development of solutions to mitigate energy use and manage electricity usage must include the residential sector. To address this, the Demand Response (DR) programs, which allow for reducing electricity peaks and valleys (valley-filling and peak shavings) are being considered [1]. It is then fundamental to rethink the electricity system, especially with respect to the management of electricity demand. Demand Side Management (DSM), which usually comprises energy efficiency and DR strategies aims to implement changes in the demand for electricity through different measures such as providing better and on-time information on tariffs, changing the existing tariff structures or promoting the use of smart devices that should support individual consumers on an active energy management.

According to the Federal Energy Regulatory Commission ( FERC), DR can be defined as "Changes in electric usage by end -use customers from their normal consumption patterns in response changes in the price of electricity over time, or to incentive payments designed to induce lower electricity use at times of high wholesale market prices or when system reliability is jeopardized" [2]. The literature usually addresses two types of DR programs: (a) Price-based Demand Response (PBDR) and (b) Incentive-based Demand Response (IBDR). PBDR, such as Time-of-Use (ToU) tariffs, Critical Peak Pricing (CPR) and Real Time Pricing (RTP), provide consumers time-varying rates, so the consumers pay for the value and cost of electricity at different times of the day. This type of DR programs is one which has been applied already to the residential sector in several countries, including Portugal. On the other hand, IBDR programs provide incentives to the consumer to reduce their electricity consumption at times defined by the grid operator. However, one of the major challenges facing the sector is how to encourage the residential consumer to change from flat-electricity tariffs to ToU or dynamic electricity tariffs, which require that consumers must be aware of the electricity price that they will pay and of the possibilities to reduce the electricity bill.

With the incorporation of new consumer habits and effective knowledge on the best electricity times of use use times to avoid overloading the electric system, i.e., to work with ToU tariffs, the consumer can save money by shifting their usage time to the off-peak, when the electricity price is cheaper, namely, during the night period. So, under these schemes the use of household appliances such as washing machines or tumble dryers should preferably happen in offpeak periods. Dynamic time tariff such as RTP, in which the price varies according to electricity market fluctuation, for example, frequently depends on the output of renewable energy power plants and will allow to reduce peak demand by automatically turning the set point of appliances such as, cooling system and heating system, in line to the price change.

However, the DR programs are not available at all times, they can vary according to the season and hour of the day and the consumers' willingness to participate may also be influenced by external factors. Factors such as, specific comfort requirements (e.g. turning off the heating or cooling system) and the lack of availability to defer householders consumption (e.g. washing machine) could result in flexibility restrictions and lower shifting rates. 
In order to study the switching and demand response behaviour of electricity users, a few surveys were already implemented, with a high focus on European countries.

For examples, a survey to the Dutch population (785 respondents) was conducted to investigate the perception of smart grid technologies and energy flexibility in the residential sector [3]. The statistical analysis demonstrated that a majority of respondents were willing to change their energy behaviour, in particular by turning off their heating system or air-conditioning, for short periods of time. A large share of residential electricity consumption belongs to these devices and their consumption is highly linked to the thermostat setting, therefore the willingness of the consumer to decrease the set point of these devices in peak period will have a significant reduction in electricity cost [4]. In the United Kingdom (UK), [5] concluded that over a third of bill payers are in favour of switching from flat-rate tariffs to ToU tariffs. The authors, [6] used a sample of (2411 residents in the UK), aimed to analyse how the public perception of energy use is driving the acceptance of Demand Side Management (DSM). The statistical results showed that the respondents were particularly concerned with affordability. Although lower income consumers have energy affordability awareness, those are less responsive to invest in smart technologies. The study showed that climate change concerns have a positive effect on the acceptance of DSM, thereby indicating that environmental issues should be used to sensitize the population in general on the potential of DSM

Using proper household data, is an important factor to provide more appropriate information for reduction of household energy consumption. Analysis of preferences of end-users, i.e., usage behaviour and appliances ownership are essential to appraise more accurately the load shifting potential. However it is important to recognize that this load shifting is limited, and programs should be designed in accordance with end-users patterns of electricity consumption [7]. Moreover, individual, social and demographic characteristics of the target population can have an impact on the effectiveness of DR to reduce peak period as the outcomes depend on the flexibility in household practices [8]. Information on how different households value electricity, different electricity needs or 'preferences' is considered essential to ensure optimal investment decisions for all sub groups of the population [9].

In this paper, we propose a methodology to evaluate the public perceptions about their electricity usage and potential flexibility for DR programs, based on a survey to be conducted in Portugal. The first phase of the study focused on an academic sample of students from one university in Portugal, with different technical backgrounds. This approach aims not only to validate the model but also to collect insights into a young and well-informed population with a high appeal for new technologies. To do that, a survey was carried out to the students of University of Minho during May 2018. are:

The central research questions associated with this paper

- What are the relevant factors influencing the students to be willing to defer their electricity usage in order to use cheaper energy?
- For how long are the students willing to defer the start of appliances usage in order to use cheaper energy (flexibility)?

- How is flexibility influenced by the cost saving potential?

The remaining of this paper is organized as follows: section 2 describes the sample and methodology used, the results and discussion are presented in section 3 and lastly, section 4 concludes the paper

\section{SURVEY DESCRIPTION}

The survey aimed to study the public perception about electricity usage. Based on the literature review a questionnaire was constructed, divided in four parts: a) sociodemographic characteristics of respondents, with 5 questions; b) dynamism/ knowledge on electricity consumption, with 4 questions; c) motivational factors for energy management, with 5 questions and d) flexibility on electricity use, with 5 questions. Whenever possible a general 5-point Likert scale was used. The questionnaire was tested and polished resorting to the comments and perceptions of a small sample of people in general and academic staff, who agreed to answer it and give feedback. It also allowed estimating the average answering time, 5-7 minutes long.

TABLE I. SOCIODEMOGRAFIC CHARACTERISTICS OF STUDENTS

\begin{tabular}{|c|c|c|}
\hline Variables & Frequency & Percentage \\
\hline \multicolumn{3}{|l|}{ Gender } \\
\hline Female & 48 & 38.40 \\
\hline Male & 77 & 61.60 \\
\hline \multicolumn{3}{|l|}{ Age (years) } \\
\hline Between 18 and 24 & 106 & 84.8 \\
\hline Between 25 and 29 & 11 & 8.8 \\
\hline More than 30 & 8 & 6.4 \\
\hline \multicolumn{3}{|l|}{ Course Enrolment } \\
\hline Under-graduate & 74 & 59.20 \\
\hline Master & 51 & 40.80 \\
\hline \multicolumn{3}{|l|}{ Nationality } \\
\hline Portuguese & 118 & 94.40 \\
\hline Other & 7 & 5.60 \\
\hline \multicolumn{3}{|l|}{ Number of residents } \\
\hline Between 1 and 2 members & 12 & 9.60 \\
\hline 3 members & 38 & 30.40 \\
\hline 4 members & 55 & 44.40 \\
\hline 5 members & 17 & 13.60 \\
\hline More than 5 members & 3 & 2.4 \\
\hline \multicolumn{3}{|l|}{ Student status } \\
\hline Student worker & 15 & 12.0 \\
\hline Full time student & 110 & 88.0 \\
\hline
\end{tabular}


Subsequently, the revised questionnaire was administered a to a sample of 125 students of University of Minho through Web-survey. The questionnaire comprised 24 questions, for which a closed format was used. Table I describes the main features of the respondents

Participants were asked to answer questions about their willingness to defer (WTD) their electricity usage, motivations to defer the usage as well how much they would need to save on their monthly electricity bill to consider deferring electricity use. The students were asked about their agreement with some sentences. This agreement was measured by 5-level Likert scale with "totally disagree"; "tend to disagree"; "tend to agree"; "totally agree" and "does not know/ does not answer". The students were also asked about their sociodemographic characteristics, average electricity bill and their knowledge about electricity tariffs. The questionnaire was carried out in Portuguese in order to make comprehension simpler and to avoid ambiguous interpretation by participants.

\section{RESULTS AND DISCUSSION}

This section is divided into four subsections, corresponding to the structure of the questionnaire. For each subsection the numeric results are presented followed by the statistical significance tests, where we intend to examine the association between the variables. For that, we conducted a two-way table of frequency count, with tests of independence for a complex survey. Given that, the Pearson's chi-square statistic is appropriate test for the survey design [10]. We proceed to the statistical significance using the Stata 15.1.

\section{A. Respondents' Characteristics}

The survey data intends to examine the information of University of Minho students' households through Google Surveys. All students could answer the survey, since it has been placed in online platform, but most of the answers were collected from engineering students. The respondents had an average age of 21.73 . From the respondents, $38.4 \%$ were female and $61.6 \%$ male. Most of them were graduate students $(59.2 \%)$ and the remaining were post-graduate (mainly master) students. A small part of the respondents were already working (12\%) and the remaining $88 \%$ were full time students. On average $3.62 \%$ person were living on their family home. Overall, a majority of respondents live in the North of Portugal, more precisely in Braga (65.60\%), Porto (18.40\%) and Viana do Castelo (5.60\%) districts.

\section{B. Dynamism and knowledge of respondents}

Besides collecting data referent to the respondent's characteristics, other factors, such as, the knowledge and dynamism of the respondents in what concerns the electricity bill were considered in the survey (Fig.1). Knowledge was assessed by asking them if they were familiar with ToU tariffs. Dynamism was proxy by three factors, namely their regular communication of the electricity consumption to the supplier, electricity supplier switching during the last two years and ownership of an electricity monitoring device (smart meter).

The results show that more than $67 \%$ of the respondents are aware of the existence of ToU tariffs, indicating a high level of knowledge. Also, most of the respondents (more than $54 \%$ ) confirm that they regularly communicate their electricity consumption to the supplier and $24 \%$ of them have a smart meter mechanism that allows to monitor their consumption. However, most of the respondents (more than 91\%) showed to be less dynamic in what concerns switching supplier, which may come from an overall satisfaction but also from the reluctance to change, as discussed for example in [11], [12].

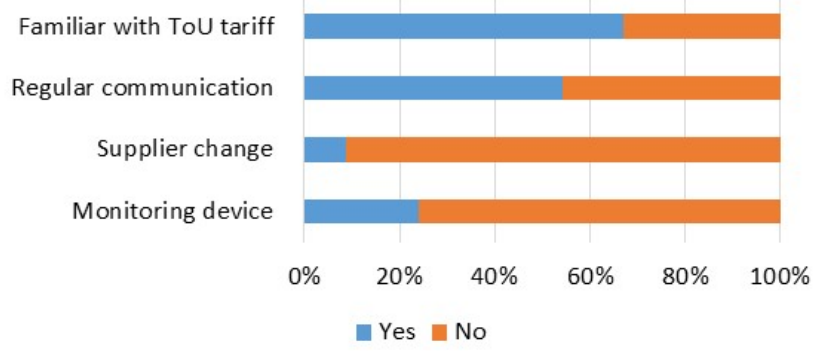

Fig. 1. The knowledge and dynamism of the respondents

The extent of the significance of different sociodemographic characteristics on the knowledge and dynamism of respondents under the null hypothesis "The level of knowledge and dynamism of respondent is independent of the sociodemographic variables" was tested as shown in table II.

TABLE II. INFLUENCE OF SOCIODEMOGRAFICS CHARACTERISTICS ON KNOWLEDGE AND DYNAMISM OF RESPONDENTS

\begin{tabular}{|c|c|}
\hline Variables & P-value \\
\hline ToUs tariff vs gender & 0.0557 \\
\hline ToUs tariff vs age & 0.8353 \\
\hline ToUs tariff vs course & 0.8506 \\
\hline ToUs tariffs vs household members & 0.0030 \\
\hline Supplier change vs gender & 0.5153 \\
\hline Supplier change vs age & 0.6090 \\
\hline Supplier change vs course & 0.8073 \\
\hline Supplier change vs household members & 0.5471 \\
\hline Regular communicate with suppler vs gender & 0.2460 \\
\hline Regular communicate with suppler vs age & 0.2396 \\
\hline Regular communicate with suppler vs course & 0.2151 \\
\hline $\begin{array}{l}\text { Regular communicate with suppler vs household } \\
\text { members }\end{array}$ & 0.0583 \\
\hline Monitoring devise vs gender & 0.4663 \\
\hline Monitoring devise vs age & 0.5184 \\
\hline Monitoring devise vs course & 0.4038 \\
\hline Monitoring devise vs household members & 0.0424 \\
\hline
\end{tabular}

However, statistical results indicate that both the knowledge and dynamism are independent of the sociodemographic variables. 


\section{Motivation factors to defer the electricity usage}

The survey contains a section that consists of several questions regarding the motivation to defer the electricity usage. This section addressed the respondents' willingness to change their daily electricity use pattern to benefit the environment; reduce importations at the national level; reduce electricity bill or to follow acquaintances advice. The description and summary statistics are presented in Fig.2.

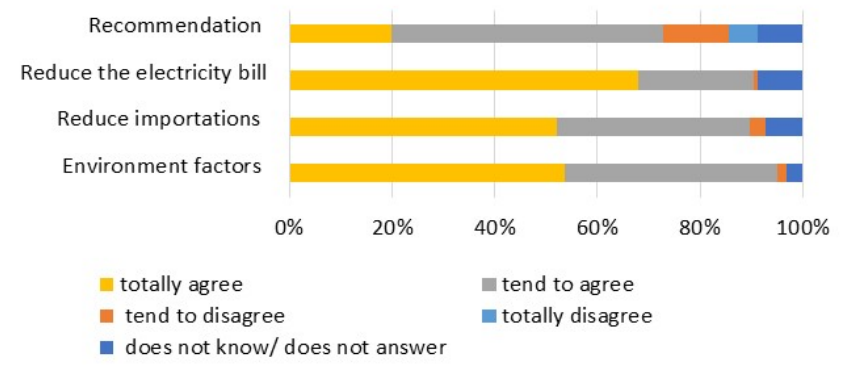

Fig. 2. Motivational factors to defer the electricity usage

All factors were considered to be relevant on the willingness to defer the energy usage, with most respondents showing a high level of WTD either driven by environmental, cost or importations motivations. On the other hand, the relevance of the social effect and recommendations although being recognized, does not play such a significant role in their decision-making process.

Table III presents the results of the statistical tests, in which the extent of sociodemographic variables influence on the motivational factors to shift the electricity usage was analysed. We worked under the hull hypothesis "The level of motivational factors is the same across the groups of sociodemographic variables". According to the Pearson's chi-square test, we verified, once again the significance for most variables is very low.

Yet the "age" is highly significant for motivating factor to the respondents to shift their electricity usage, and variable "course" is significant for the respondents shift their electricity usage motivated by environmental factors and recommendation of someone's else. The results indicate that younger respondents are more motivated to shift their electricity usage driven by economic factors, environmental factors and energy dependence and are also more available to obtain good advice from other people. The results indicate that younger respondents are more motivated to shift their electricity usage driven by economic factors, environmental factors and energy dependence and are also more available to obtain good advice from other people. These results should however be looked with caution, given that the sample can be biased by a large number of younger respondents. The significance of age will be analysed with further detail in the future study for the entire population.

Moreover, the variable "course", related to the course that students are attending, was also statistically significant. The majority of students who attend engineering courses, especially MSc in Industrial and Management Engineering and MSc in Industrial Electronics and Computer Engineering tend to be more sensitive to environmental factors and follow acquaintances advice.
TABLE III. INFUENCE OF SOCIODEMOGRAFICS CHARACTERISTICS ON THE MOTIVATIONAL FACTORES TO SHIFT THE LECTRICITY USAGE

\begin{tabular}{|c|c|}
\hline Variables & P-value \\
\hline Environmental factors vs gender & 0.1720 \\
\hline Environmental factors vs age & 0.0001 \\
\hline Environmental factors vs course & 0.0000 \\
\hline Environmental vs household members & 0.5825 \\
\hline Reduce of electricity bill vs gender & 0.3308 \\
\hline Reduce of electricity bill vs age & 0.0000 \\
\hline Reduce of electricity bill vs course & 0.1978 \\
\hline Reduce of electricity bill vs household members & 0.4876 \\
\hline Reduce of energy imports vs gender & 0.2022 \\
\hline Reduce of energy imports vs age & 0.008 \\
\hline Reduce of energy imports vs course & 0.0956 \\
\hline Reduce of energy imports vs household members & 0.9646 \\
\hline Recommendation vs gender & 0.1030 \\
\hline Recommendation vs age & 0.0010 \\
\hline Recommendation vs course & 0.0002 \\
\hline
\end{tabular}

\section{Flexibility electricity demand}

In this study, the willingness to defer the start of a given domestic appliances (e.g. washing and dryer machines) according to respondents' electricity bill per month was considered (Fig.3; Fig.4 and Fig.5). In building the survey we have taken into account the absolute values are adjusted according to the average electricity bill.

An overwhelming majority of respondents demonstrated to be available to defer the use of domestic appliances. According to the results, it is possible to observe that saving expectations can play some role on the consumers' flexibility, as the share of consumers "tending to disagree" or "totally disagreeing" tend to decline when higher savings can be obtained. However, the extent of the impact of this economic factor may be limited by low absolute values of these savings. For example, for one consumer with an electricity bill of around $100 €$ per month, the maximum saving would be close to $6 €$ which may not be sufficiently appealing to justify major changes on their electricity usage.

Moreover, when asked about their willingness to defer for more than six hours, the interviewees have shown some reluctance in postponing the use of domestic appliances even for higher cost saving. One possible reason for the respondents to be less available to defer their consumption could be due to their work life and daily routines. 


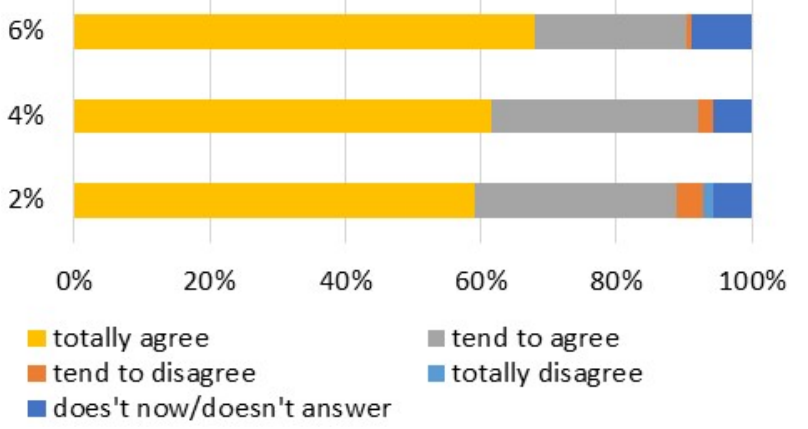

Fig. 3. Willingness to defer electricity usage for 1-2 hours against potential cost saving

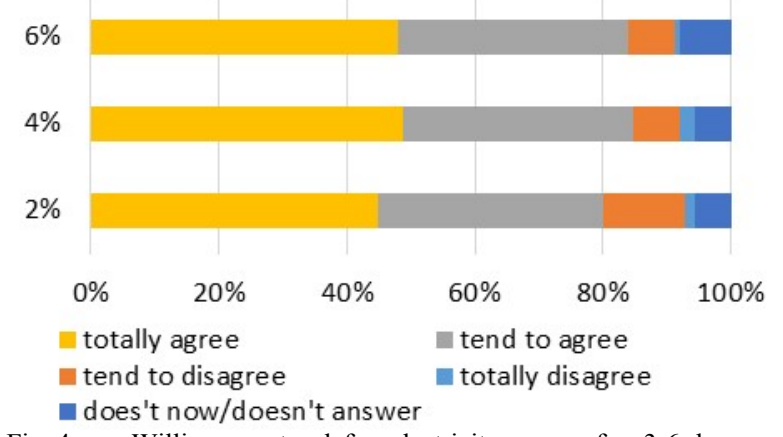

Fig. 4. Willingness to defer electricity usage for 3-6 hours against potential cost saving

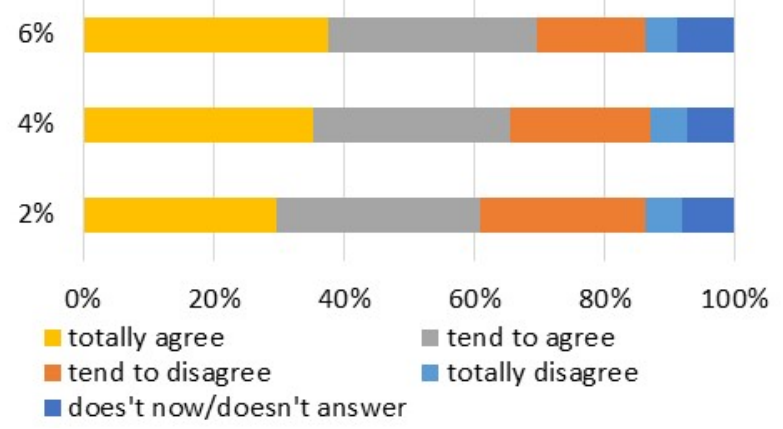

Fig. 5. Willingness to defer electricity usage for more than 6 hours against potential cost saving

The present study also included the assessment of the consumers' willingness to change the energy based on some automatic device. This should support electricity management if dynamic tariffs, such as RTP, were available. The respondents were questioned in particular, if they would be available to set the temperature of their heating or cooling system on automatic mode to take advantage of the possible tariff changes (fig.6). A vast majority of respondents totally agree or tend to agree with this possibility, which can be related to the characteristics of the target population, namely young, with high academic level and high appeal for new technologies. automatic mode
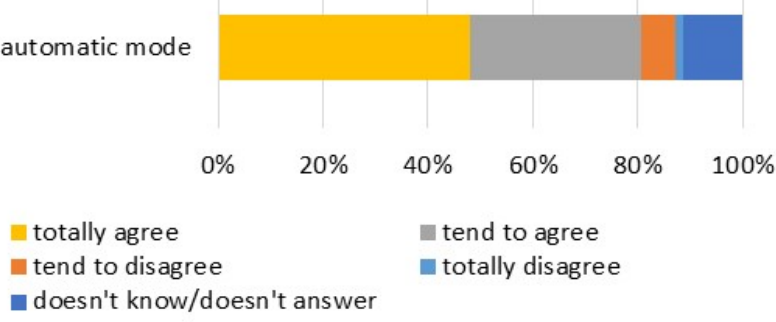

Fig. 6. Willingness to defer the use of the heating and cooling system

On table IV we can evaluate how sociodemographic variables could have influence the willingness to accept this kind of automatic control. The null hypothesis was formulated as: "The level of willingness to accept the automatic control of the temperature set point of the heating and cooling system is independent of sociodemographic variables". According to the results the variables "age" and "course" have effect on the willingness to accept the automatic control of the heating or cooling system, i.e., the younger people and the students that attending $\mathrm{MSc}$ in Industrial and Management Engineering and MSc in Industrial Electronics and Computer Engineering are more available to set their heating or cooling system in automatic mode to benefit from electricity price fluctuations.

TABLE IV. INFUENCE OF SOCIODEMOGRAFICS CHARACTERISTICS ON ACCEPTANCE OF AUTOMATIC SET POINT CONTROL

\begin{tabular}{|l|c|}
\hline Variables & P-value \\
\hline Acceptance of set point control vs gender & 0.7916 \\
\hline Acceptance of set point control vs age & 0.0000 \\
\hline Acceptance of set point control vs course & 0.0047 \\
\hline Acceptance of set point control vs household members & 0.9789 \\
\hline \multicolumn{2}{|c|}{$\begin{array}{r}\text { Notes: The results are statistical significant for p-values lower than 0.05. The command svy: } \\
\text { tabulate was used specifically to produce the two-way table for complex survey. }\end{array}$}
\end{tabular}

Besides of the influence of sociodemographic variables, other variables, such as, environmental factors and reduce of energy imports were considered. Under the null hypothesis:" The level of willingness to accept the automatic control of the temperature set point of the heating and cooling system is independent of environmental factors perception" was tested. The results demonstrate that null hypothesis was rejected ( $p$ value $=0.0001)$, and those of acknowledge the importance of environmental factors on their decision-making process, tend to better accept this automatic scheme. Also, the null hypothesis:" The level of willingness to accept the automatic control of the temperature set point of the heating and cooling system is independent the imported energy perception". The results suggest that importance assigned to reduction of the energy imported is statistically correlated to the acceptance of this automatic schemes ( $p$-value $=0.0230$ ). These results disclose that environmental factors and the concern in to reduce dependence on imported energy can play an important role on adoption of DR programs, especially when targeting young, population with a high academic background. 
Knowledge and dynamism of the respondents' influence on acceptance of DR program was also analysed. Under the null hypothesis "the level of dynamism of respondents is independent of the acceptance of automatic control of the temperature set point of the heating and cooling system" was tested. In line to the result of the Pearson's chi-square test the null hypothesis was confirmed ( $p$-value $>0.1$ ), which suggests that the dynamism of respondents may not influence the acceptance of the DR programs.

\section{CONCLUSIONS}

This paper intended to investigate the public perception about electricity usage. A Web-survey with a sample 125 of students from University of Minho was conducted. According to the statistical analysis more than $60 \%$ of respondents were familiar with terms such a "bi-horário and tri-horário", i.e., the students acknowledge the possibility of switching from flat rate electricity tariffs to ToUs tariffs.

The results indicate that consumers are sensitive to cost savings, which opens up good perspectives for the use of economic incentives to encourage end-users to shift their electricity usage during off-peak periods. However, we observed that some of respondents do not demonstrate willingness to defer consumption for more than six hours, since there is a limited load shifting potential given the enduser's daily routines. Willingness to defer the electricity usage seems to depend on the potential bill savings, as the higher is the potential saving the higher is the acceptance ratio. Notwithstanding, as Figures 3-5 show, the flexibility is limited and tends to decline for longer periods of deferment.

Amongst the main motivating factors for the respondents' willingness to defer their electricity usage, the reduction of the electricity bill, emerges the most relevant one. More than $68 \%$ of the respondents' state that they would totally agree on changing their electricity pattern if this would lead to a reduction on the electricity cost. However, environmental factors, and reduction of dependency on energy imports are also significant for the decision-making process, which can be justified by the target population characteristics.

A large majority of respondents were willing to change their energy use behaviour resorting to some automatic systems. More than $80 \%$ considered the possibility of automatic control for the heating and cooling system to take advantage of the electricity market fluctuations. This opens important avenues for future research and technical developments, showing that the demand response programs can be effectively achieved, and new tariff schemes should be considered.

Smart technologies, such as, smart meter and in-home displays encourage the end-users to have a more responsible energy behaviour, however the effective adoption of DR programs is strongly influenced by consumer's daily routines. The results in general underline this trend: a high interest and willingness for managing electricity demand at home but with limited flexibility even if higher savings could be achieved.
To sum up, this study provides some crucial topics when designing new energy policies and helps the energy suppliers to develop and implement strategies for the promoting of more willingness to the end-users to switch their energy use and even change their daily pattern. The development of awareness campaigns on the use of ToUs tariffs and their advantages in order to encourage people to switch their electricity tariff, emerge as a fundamental strategy. Moreover, the importance assigned to environmental factors and concerns about energy dependence of the country should not be overlooked on these awareness campaigns. However, the results of this research are highly influenced by the target population and should be seen as an exploratory study within a larger study to be implemented at national scale.

\section{ACKNOWLEDGMENT}

This work is financed by the ERDF - European Regional Development Fund through the Operational Programme for Competitiveness and Internationalisation COMPETE 2020 Programme, and by National Funds through the Portuguese funding agency, FCT Fundação para a Ciência e a Tecnologia, within project SAICTPAC/0004/2015 POCI/01/0145/FEDER/016434.

\section{REFERENCES}

[1] I. A. Nienhueser and Y. Qiu, "Economic and environmental impacts of providing renewable energy for electric vehicle charging - A choice experiment study," Appl. Energy, vol. 180, pp. 256-268, 2016.

[2] U.S. Departmentof Energy, "BENEFITS OF DEMAND RESPONSE IN ELECTRICITY MARKETS AND RECOMENDATIONS FOR ACHIEVING THEM," no. February, pp. 1-122, 2006.

[3] R. Li, G. Dane, C. Finck, and W. Zeiler, "Are building users prepared for energy flexible buildings?-A large-scale survey in the Netherlands," Appl. Energy, vol. 203, pp. 623-634, 2017.

[4] A. Asadinejad, A. Rahimpour, K. Tomsovic, H. Qi, and C. Chen, "Evaluation of residential customer elasticity for incentive based demand response programs," Electr. Power Syst. Res., vol. 158, pp. 26-36, 2018

[5] M. Nicolson, G. Huebner, and D. Shipworth, "Are consumers willing to switch to smart time of use electricity tariffs? The importance of loss-aversion and electric vehicle ownership," Energy Res. Soc. Sci., vol. 23, pp. 82-96, 2017.

[6] A. Spence, C. Demski, C. Butler, K. Parkhill, and N. Pidgeon, "Public perceptions of demand-side management and a smarter energy future," Nat. Clim. Chang., vol. 5, no. 6, pp. 550-554, 2015.

[7] M. A. R. Lopes, C. Henggeler Antunes, K. B. Janda, P. Peixoto, and N. Martins, "The potential of energy behaviours in a smart(er) grid: Policy implications from a Portuguese exploratory study," Energy Policy, vol. 90, pp. 233-245, 2016.

[8] L. Nicholls and Y. Strengers, "Peak demand and the 'family peak' period in Australia: Understanding practice (in)flexibility in households with children," Energy Res. Soc. Sci., vol. 9, pp. 116124, 2015.

[9] K. Morrissey, A. Plater, and M. Dean, "The cost of electric power outages in the residential sector: A willingness to pay approach," Appl. Energy, vol. 212, no. December 2017, pp. 141-150, 2018.

[10] D. Taylor-linearized, "Stata.Com," Stata J., pp. 1-20.

[11] M. Six, F. Wirl, and J. Wolf, "Information as potential key determinant in switching electricity suppliers: An econometric study on Austrian households," J. Bus. Econ., vol. 87, no. 2, pp. 263-290, 2017.

[12] Y. Yang, "Understanding household switching behavior in the retail electricity market," Energy Policy, vol. 69, pp. 406-414, 2014. 